\title{
A Mathematical Polyglot
}

\author{
Elisabetta Strickland (University of Rome Tor Vergata, Italy), EMS-WIM Committee
}

On 13 August 2014, when Maryam Mirzakhani entered the main hall of the COEX, a gigantic conference centre in Seoul, South Korea, the Opening Ceremony of the 27th ICM (the International Congress of Mathematicians) was about to start. The 5000 people sitting there were all waiting for the names of the four Fields Medallists to be announced and all the women in the audience were incredibly excited, as rumours had been circulating that for the first time a woman would be among the winners and that that woman would be Maryam. As a fortunate circumstance, she was sitting close to me, as the delegates to the IMU General Assembly, which had taken place three days before in Gyeongju, had been positioned close to the Fields Medal winners. I really couldn't resist reaching over to her. I noticed immediately her grey-blue eyes and her interesting expression: she didn't show any outward emotion; she obviously had an unwavering selfconfidence and, at the same time, a fundamental humility. In my excitement, I asked her if she sensed the strong feelings about the meaning of her presence there for all the women mathematicians in the hall. I noticed that she was moved by my words and she simply and gracefully shook my hand and smiled, whispering "Thank you".

Then, her name was officially announced with those of the other three Medal winners: Artur Avila, Manjul Bhargava and Martin Hairer. A novel feature of the ceremony were short films about the winners, produced by Jim Simmons, the American mathematician, hedge fund manager and philanthropist, who, through his foundation, supports projects in mathematics and in research in general. We could all see on the screen Maryam in her home in Palo Alto, California, kneeling with a felttip pen in her hand, doodling on vast white sheets of drawing paper unrolled on the floor of her room, to the amusement of her toddler Anahita, who believed she was painting instead of drawing Riemann surfaces.

I'll never forget the roar that went up in the hall when her name was announced. Tears came to our eyes and we stood up screaming in joy because, all of a sudden, it was true: for the first time after so many editions of the ICM since 1897, a woman had received the Fields Medal, the most coveted award in mathematics. The citation by the IMU Fields Medal Committee was "for her outstanding contributions to the dynamics and geometry of Riemann surfaces and their moduli spaces".

Maryam was 37 years old at the time. Even if some of us had been informed that she was undergoing therapy for breast cancer, we dismissed the thought from our minds; this was a time for optimism. Unfortunately, three years later we learned that her body hadn't succeeded in remission from the disease and the cancer had spread to her bones. In July 2017, she died.

Since that magic day in Seoul, she did some fantastic work in the world of billiard tables, a profound and

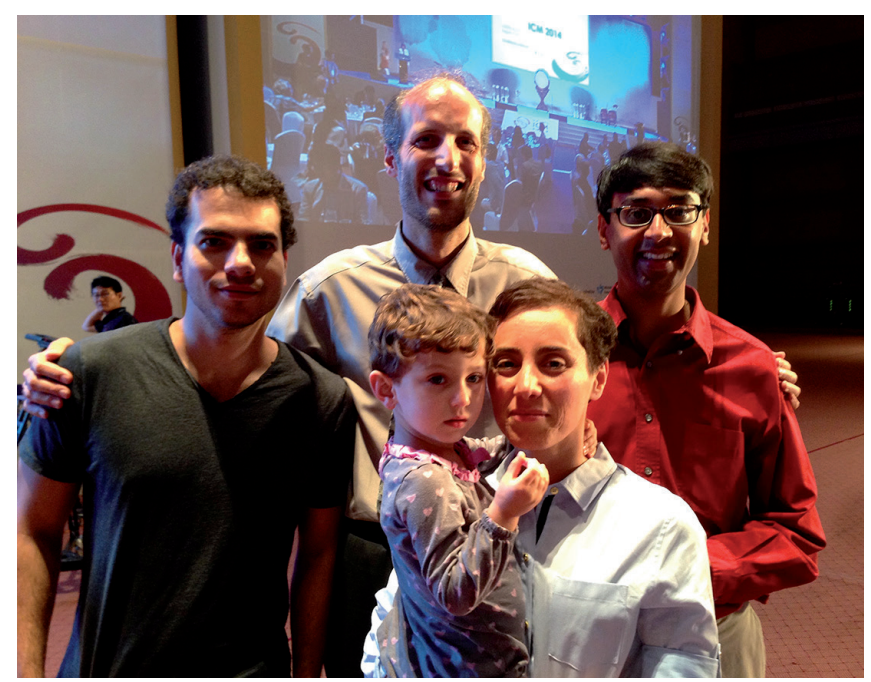

Maryam Mirzakhani in Seoul, together with the other Fields Medal winners: Artur Avila, Manjul Bhargava and Martin Hairer.

Author: Gert-Martin Greuel. Source: Archives of the Mathematisches Forschunginstitut Oberwolfach.

modern mathematical subject. She developed this work together with Alex Eskin and partly in collaboration with Amir Mohammadi. The crowning result of this work, by some considered one of the most important of the decade, is now known as the "Magic Wand theorem".

Reading her biography, one finds out that until mathematics attracted her, she planned to become a novelist. It was only later in her school career that she discovered that she achieved a special understanding of mathematics, thanks to an encouraging teacher, so she switched her interest to science. In the Iran of her childhood, books cost very little and she read so many that later her maths had a literary tinge, as if the problems she studied were the characters of a fascinating plot. She just had to do her best to know them and work them out.

Maybe her early passion for literature was also the reason for her being, by her own admission, a "slow" mathematician: her husband, Jan Vondrak, an electrical engineer and theoretical computer scientist at IBM Almaden Research Center in San José, California, joked about her steady approach to all areas of her life. He used to tell a story that went back to their graduate student days, she at Harvard, he at the Massachusetts Institute of Technology. They used to go jogging together and while he would initially run faster and keep ahead, eventually he would tire, while her slow but steady pace meant she would overtake him and arrive first.

She was so smart in school that she entered the Tehran Farzanegan School, an institution for educationally gifted girls. Then, she was the first girl, together with her friend and schoolmate Roya Beheshti, to represent her country in the Mathematics Olympic Games, winning gold medals for two successive years, in 1994 in Hong 
Kong and in 1995 in Toronto. After graduating from Sharif University in Tehran, she followed a path taken by many Iranian students, as she left for the United States for postgraduate studies and in 2004 obtained her $\mathrm{PhD}$ at Harvard, under the doctoral supervision of Curtis McMullen, a fellow Fields Medal winner.

She obtained a job in Princeton immediately after and then moved to Stanford in 2008 as a full professor. This means that she had a first class career far from her country but was always grateful to her native Iran, as she experienced first-hand how the education and careers of women were encouraged. Being not only the first woman to win the Fields Medal but the first Iranian, she became a celebrity in her country, so much so that, after her death, the media gave up portraying her with a headscarf, showing instead an Iranian woman with short hair, her head uncovered. This meant that officials allowed editors to ignore Iran's strict dress code for female pictures to mark her death. She remained a heroine for many of her fellow countrymen, including President Hassan Rouhani, who released a condolence message about her "unique brilliance and contribution to scientific progress of Iranian women".

While Maryam was not easily disappointed and was always confident in herself, when she was told by email that she had been awarded the Fields Medal, she ignored the message, assuming it was a joke. She resisted pressure to be a role model because she believed that many other women were also doing great things in mathematics. But she believed that discouragement is a real problem for female mathematicians, as the peak years of mathematical productivity often coincide with the time in life that women give birth and care for small children. So, when she won the medal, she expressed the hope that her award would encourage young female mathematicians.
Stanford University had to work hard on press releases in order to explain her specialisation in the geometry and dynamics of complex curved surfaces, an abstract field that reads like an obscure foreign language to non-mathematicians. The Stanford press release states that she worked on "moduli spaces, Teichmüller theory, hyperbolic geometry, ergodic theory and symplectic geometry", an astonishing variety of fields. This is like stating that she was a mathematical polyglot. In addition to their beauty and complexity, her results in these fields will help physicists and cosmologists to investigate the fundamental nature of the universe.

After her death, Stanford President Marc TessierLavigne said that "Maryam has gone far too soon but her impact will live on for the thousands of women she inspired to pursue mathematics and science". We can only agree with these words.

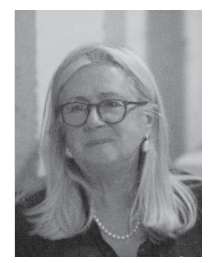

Elisabetta Strickland is a full professor of algebra at the Department of Mathematics of the University of Rome "Tor Vergata". She was Deputy President of the National Institute of Advanced Mathematics (INdAM) from 2007 to 2015. Since 2014, she has been a member of the Women in Mathematics Committee (WIM) of the European Mathematical Society. She is also a co-founder of the Gender Interuniversity Observatory GIO over the state universities in Rome. Since 2016, she has been an Ambassador of Italy on the Committee of Women in Mathematics (CWM) of the International Mathematical Union. In 2013, she was awarded the "Excellent Women in Rome" Prize from the Capitoline Administration. 